\title{
Rescuing the physician-scientist workforce: the time for action is now
}

\author{
Dianna M. Milewicz, ${ }^{1}$ Robin G. Lorenz, ${ }^{2}$ Terence S. Dermody, ${ }^{3}$ Lawrence F. Brass, ${ }^{4}$ \\ and the National Association of MD-PhD Programs Executive Committee ${ }^{5}$
}

'Department of Internal Medicine, University of Texas Health Science Center at Houston, Houston, Texas, USA. ²Department of Pathology, University of Alabama at Birmingham, Birmingham, Alabama, USA. ${ }^{3}$ Departments of Pediatrics and Pathology, Microbiology, and Immunology, Vanderbilt University School of Medicine, Nashville, Tennessee, USA. ${ }^{4}$ Departments of Medicine and Pharmacology, University of Pennsylvania, Philadelphia, Pennsylvania, USA. ${ }^{5}$ The National Association of MD-PhD Programs Executive Committee is detailed in the Supplemental Acknowledgments.

The 2014 NIH Physician-Scientist Workforce (PSW) Working Group report identified distressing trends among the small proportion of physicians who consider research to be their primary occupation. If unchecked, these trends will lead to a steep decline in the size of the workforce. They include high rates of attrition among young investigators, failure to maintain a robust and diverse pipeline, and a marked increase in the average age of physician-scientists, as older investigators have chosen to continue working and too few younger investigators have entered the workforce to replace them when they eventually retire. While the policy debates continue, here we propose four actions that can be implemented now. These include applying lessons from the MD-PhD training experience to postgraduate training, shortening the time to independence by at least 5 years, achieving greater diversity and numbers in training programs, and establishing Physician-Scientist Career Development offices at medical centers and universities. Rather than waiting for the federal government to solve our problems, we urge the academic community to address these goals by partnering with the NIH and national clinical specialty and medical organizations.

In June 2014, the NIH Physician-Scientist Workforce (PSW) Working Group completed a year of data collection and deliberation, and released a report about the status of the PSW (1). The report is a combination of good news and bad news. The good news is that, despite the decline in the NIH budget, the size of the PSW has remained relatively stable. The bad news is that the current demographics, diversity, and career progression of this workforce raise concerns about the future. For a start, although apparently stable in size, the PSW is even smaller than many of us realized, and the apparent stability has hidden important demographic trends. In American Medical Association surveys of the nearly 1 million (and rising) MD physicians in the United States, only 14,000 (1.5\%) consider research to be their primary focus (1). Even fewer have NIH grant support; only 8,200 physicians are principal investigators on NIH grants, split evenly between MDs and MD-PhDs (1). The number of extramural NIH-funded physician-scientists with research program ( $\mathrm{R}$ series) awards has been essentially constant for the past 20 years, while the number of nonphysician (PhD) NIH-funded investigators has increased by half over the same period, reaching 19,400 in 2012 (1). As a result, the percentage of NIH awardees who are physicians has fallen to $30 \%$. Although public policies have encouraged an increase in the number of medical schools and medical students in the US, and medical school admission policies have placed value on undergraduate research, the percentage of physicians focused on research has fallen.

Conflict of interest: The authors have declared that no conflict of interest exists Reference information: J Clin Invest. 2015;125(10):3742-3747. doi:10.1172/JCI84170.
At the same time that the PSW has remained stable in size, data in the report show that the average age of the workforce is rising, as older investigators remain employed and younger investigators have not emerged in sufficient numbers. The average age at which a physician-scientist received his or her first NIH R01 grant in 2011 was 44 years for MD-PhDs and 45 years for MDs: approximately 10 years older than in 1980 (2). R01-funded investigators (physicians and nonphysicians) younger than 37 years have all but disappeared, and the time from graduating medical school to obtaining a first faculty position has increased to over 10 years for $\mathrm{MD}-\mathrm{PhDs}$ and even longer for MDs without a $\mathrm{PhD}$. Women and minorities are underrepresented, having opted not to enter or remain in the workforce. Thus, gathering places for physician-scientists look mostly like clubs for older white men. Without corrective action, the PSW appears headed for a population crash as older investigators retire. We recognize that younger physician-scientists have not entirely disappeared; they just take longer to obtain faculty appointments and independent NIH grants. This situation creates an extended waiting period that we call the holding zone, which contributes to the disturbing demographics (Figure 1).

\section{Enough talk, let's do something}

The NIH advisory group noted these trends and made recommendations that should be considered (1). Rather than repeating them here, we would like to join the discussion by adding the perspective of four NIH-funded physician-scientists and educators who lead long-established MD-PhD training programs at our respective institutions. The views are our own but also reflect those of the other members of the Executive Committee of the National Association of MD-PhD Programs, an organization that each of us has 


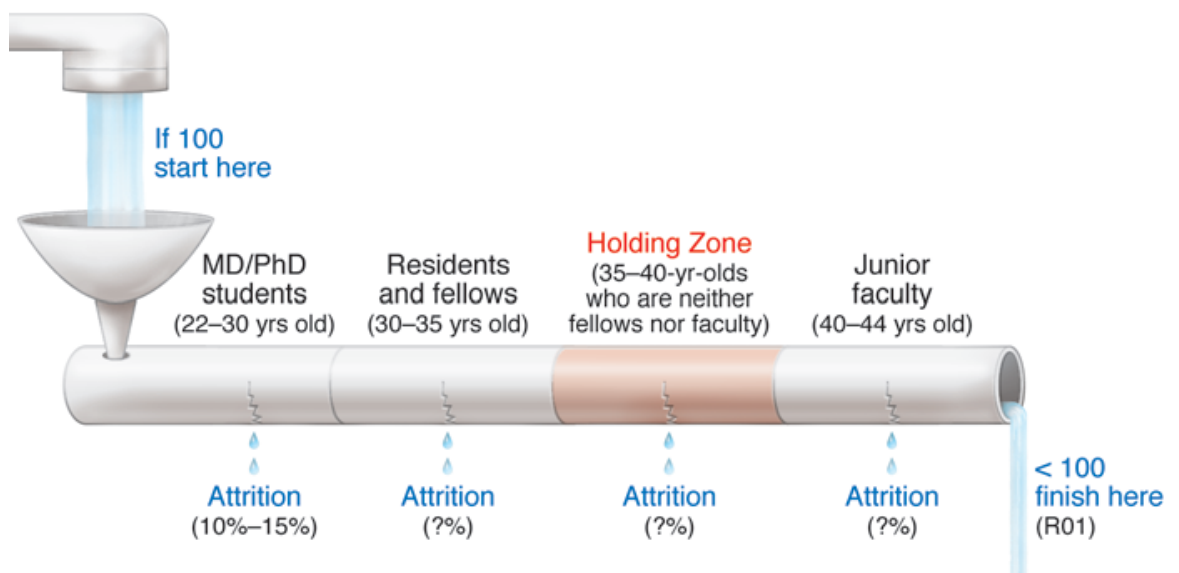

Figure 1. The physician-scientist pipeline: long and leaky. The figure highlights a number of issues, including career attrition at every stage and the existence of a protracted period when well-trained physicians in their $30 \mathrm{~s}$ are serving in subordinate positions awaiting the next step in their career progression. To draw attention to their plight, we call this period the holding zone. The illustration is based on the experience of MD-PhD program graduates, but many of the issues reflect the obstacles for any would-be physician-scientist. Attrition rates from MD-PhD programs are low, with most of those who withdraw completing medical school or graduate school. Very few MD-PhD program graduates ( $5 \%$ or fewer) choose to forego postgraduate clinical training as residents and fellows. In our experience, career attrition takes many forms and becomes cumulative at each stage, reflecting the proportion of individuals who either never return to research, opt for fulltime clinical practice outside of academia, join academia as an assistant professor but spend their time caring for patients, or are appointed to the tenure track but end up devoting minimal time to research (1). A declaration of success depends in part on the definition of success. Outcome data show that approximately $80 \%$ of MD-PhD program graduates are working in academia, industry, or research institutes - including the NIH - but not all are doing research (3). Data on NIH award rates, conversions from $\mathrm{K}$ grants to R grants, and the proportion of individuals appointed to MSTP T32 grants can be found in the PSW report (1). The NIH continues to track principal investigators on grants but is just starting to track physician-scientists who play essential roles as other key personnel.

led. Our action plan focuses on four ideas that can be implemented now to sustain the PSW: (i) apply lessons from the MD-PhD training experience to postgraduate training; (ii) shorten the time to independence by at least 5 years; (iii) achieve greater diversity and numbers in training programs; and (iv) better organize physicianscientist mentoring and oversight at all levels to reduce attrition. We note that much of this can be accomplished without new funds from the NIH, but we urge that the goals be addressed through a partnership between the NIH, national clinical and medical organizations, and academic medical institutions.

\section{Action item \#1: Apply the lessons from the MD- PhD training experience to postgraduate training of physician-scientists}

MD-PhD training programs started in the 1950s, with the first NIH Medical Scientist Training Program grants (MSTP grants) awarded in 1964. In the 50 years since, they have proven to be an effective approach for training physician-scientists. Our first action item is to apply lessons learned from $\mathrm{MD}-\mathrm{PhD}$ training to postgraduate training of physician-scientists.

Integrate medical and research training. $\mathrm{MD}-\mathrm{PhD}$ programs were initially organized to include 2 years of preclinical coursework, followed by 3 or more years of graduate school, followed by 2 years of clinical training to complete medical school. Over the past 20 years, this approach - in which there is little cross-connection between medical and graduate training - has been gradually supplanted by integrated strategies in which graduate studies begin sooner and clinical studies are often initiated prior to and continue during graduate school. Although the extent of integration varies widely, the shift in approach has taken advantage of medical education trends that allow greater curricular flexibility and intro- duce full-time clinical experiences earlier in medical school. Such integration of medical and research training has been neglected in postgraduate education, which is typically segregated into long periods of clinical training divorced from research, especially labbased research. As a result, future physician-scientists often spend years away from the research environment, making their reentry that much more difficult. A lesson from the MD-PhD program is that integration can and should be encouraged.

Share best practices and collect outcome data. The trend toward integrated training in $\mathrm{MD}-\mathrm{PhD}$ programs paralleled the emergence in the 1990s of an annual meeting of MD-PhD program directors and administrators. Leaders of MD-PhD programs from approximately 75 medical schools currently meet annually to share best practices, exchange data and ideas, and help to develop new program leaders and administrators. Although programs collect outcome data individually, these meetings have led to the collection of training metrics and outcomes for MD-PhD programs nationally, including data about whether graduates establish independent and productive research careers. These data led to the first broad-based analysis of MD-PhD program outcomes in 2008, which showed that approximately $80 \%$ of those who had completed all phases of training were employed as either faculty members at medical schools, scientists at research institutes, or investigators in the biotech and pharmaceutical industries (3). A followup nationwide survey of the $10,500 \mathrm{MD}-\mathrm{PhD}$ program alumni to date is currently underway, with support from the American Association of Medical Colleges (AAMC). Based on our successful experience, we urge the formation of a professional organization that promotes the sharing of best practices and collection of outcome data for research-focused residency and fellowship programs as a key element to improving and shortening postgraduate physician-scientist training. 
A

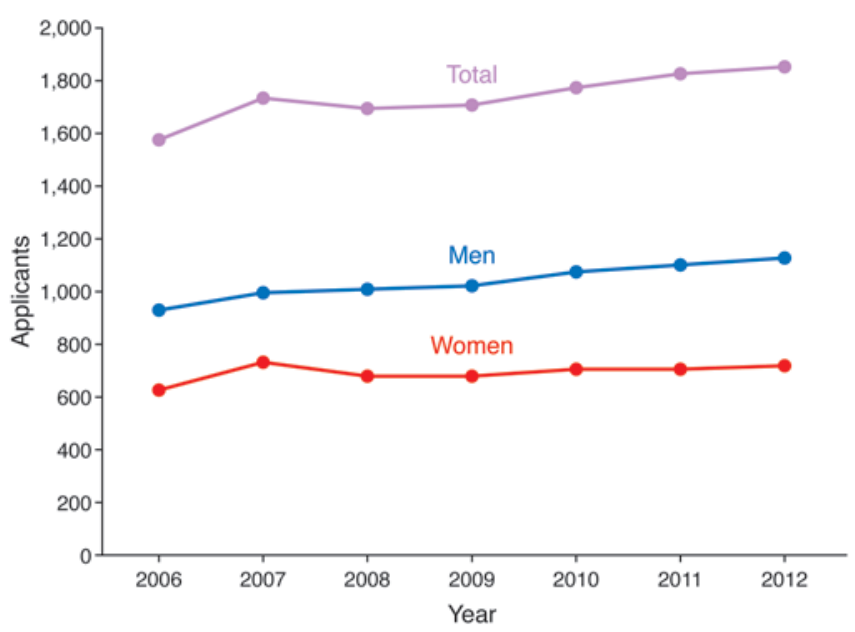

B

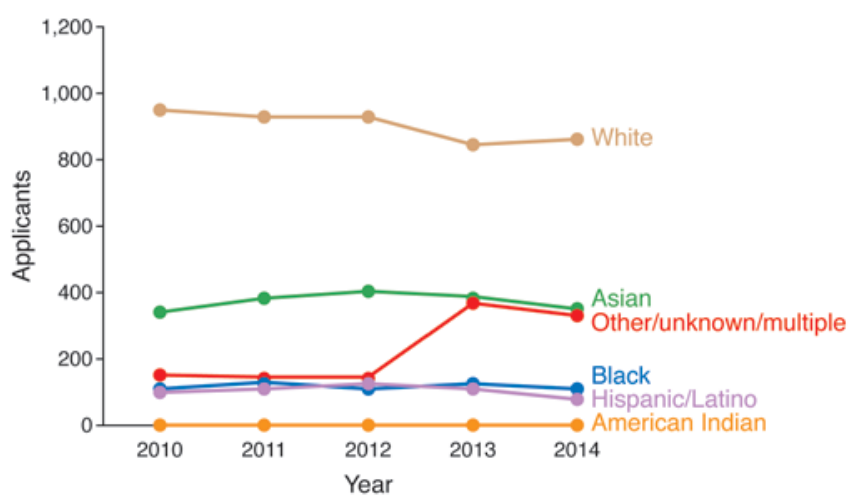

Figure 2. Women and underrepresented minorities are not entering the pipeline. (A) Although the number of graduates from MD-PhD programs has risen over the past 10 years, women are less likely to apply to these programs than men (30). (B) The number of underrepresented minority applicants to MD-PhD programs did not increase between 2010 and 2014 (31).

Acquire strong institutional support. $\mathrm{MD}-\mathrm{PhD}$ programs are expensive. Although NIH training and research grants support some of the costs, institutional investments are substantial in terms of funds, faculty time, and research infrastructure. These well-organized institutional efforts that enable modern MD-PhD training programs should also be applied to improve the quality of postgraduate physician-scientist training, reduce attrition, and shorten the time to independence. Suggestions about how to organize these institutional efforts are provided in action item \#4.

\section{Action item \#2: Shorten the time to an independent research position by at least 5 years} The years following completion of formal postgraduate clinical training make up a critical time in the development of a physicianscientist. This interval is occupied primarily by additional research training and is often incorporated into a postdoctoral fellowship. This time used to be relatively short, with appointment to a faculty position commonly occurring within a year or two of finishing a fellowship. A physician-scientist's first faculty appointment now occurs at age 40 years or older, with the first independent NIH grant obtained at approximately 45 years. This extended training interval is not due solely to increased specialty board requirements, although these requirements may be a contributing factor. From our experience, the time to first faculty appointment has grown longer because of greater expectations on the part of department chairs. The net effect is a prolonged period during which well-trained physicians in their 30s, a time when many are starting families, wait to begin independent careers. This holding zone is filled with uncertainties and increased potential for attrition. Ironically, we think that mentored NIH K awards may have the unintended consequence of contributing to the duration of the holding zone by requiring extensive postdoctoral research productivity, limiting the ability to apply for other NIH grants, not providing sufficient resources for independent research, and often serving as a prerequisite for a faculty appointment. Our second action item is to urge new training, funding, and hiring practices that will shorten the time from medical school graduation to first faculty appointment by at least 5 years.

Establish and evaluate clinical training programs that better integrate research. We start with the perspective that it is undesirable to remove future physician-scientists from the research setting to do 3 or more years of full-time clinical training and that doing so increases attrition. Currently approved research residency programs are available in internal medicine, pediatrics, pathology, radiology, radiation oncology, and dermatology (4-10). There is a need for comprehensive evaluations of the outcomes of these programs in terms of physician-scientist training and careers. At present, the only available data show that the American Board of Internal Medicine Research Pathway does not adversely affect internal medicine certification status, and that $63 \%-72 \%$ of graduates hold positions in academic medicine and continue to devote a substantial portion of their time to research $(11,12)$. There are no national standards for core curricula or for residency and fellowship research requirements. A starting point for establishing these standards should be derived from institutions that have excellent physician-scientist training programs (PSTPs), including the University of California at Los Angeles STAR Program (13) and the Washington University PSTP (14). These programs have established that protected time for research, adequate mentoring, and a focus on career guidance and individual career development goals are critical for the retention of physician-scientist trainees in academic medicine and research.

In addition to this focus on well-established programs, innovative approaches should be explored to determine the optimal clinical and research training during residency and fellowship, since many future physician-scientists do not choose to complete their residencies within these established pathways (15). There have been several recent examples of unique strategies that have allowed for combined research and clinical experiences for physician-scientists training in the field of psychiatry (16-18). Although these unique pathways appear to work well in a single discipline, they have not been tested in other specialties that differ in their length and curricular requirements. The NIH can help by funding pilot grants for innovative approaches to research-track residency and fellowship training.

Improve transition to independence awards: earlier grants better tailored for physician-scientists. Current mentored NIH career development awards, including the K08 and K23, are often used to bridge formal research training to independent faculty positions. K awards have been successful in that $42 \%$ are eventually converted to R01 grants (1), but they have the unintended consequence of prolonging the 
training interval and delaying independence if NIH K award study sections require greater and greater years of experience and productivity (e.g., preliminary data and manuscripts) before an award is made. Additionally, $\mathrm{K}$ awards have restrictive policies that may slow or limit the awardee's ability to become an independent investigator. Specifically, K awardees cannot be principal investigators on additional NIH grants until the final 2 years of the K award, nor can they serve as co-PIs on NIH grants, which makes it difficult for awardees to initiate collaborative studies or contribute to research teams.

Based on these concerns, we concur with the recommendation in the PSW report that a K99/R00 award should be established specifically for physician-scientists. The duration of K99 support should begin during (not after) the fellowship and be no more than 2 years. The R00 period should be extended from 3 to 5 years, contingent on satisfactory progress and establishment of an independent position. An extended period of R01-level funding would provide time for physician-scientists to recruit research teams, gather data, and publish findings, and it would make junior physician-scientists more attractive hires for department chairs. We further propose that the K99/ R00 award should be renewable to an R01 grant (with such applications, provided new investigator status) to enable physician-scientists to demonstrate continuity of funding. This mechanism would be very attractive for $\mathrm{MD}-\mathrm{PhDs}$ who already have significant research training and should be able to transition more rapidly to independence. R00 budgets should be boosted to levels of R01 grants, and along with institutional startup funds and protected time, the R00 should form the basis for independent research as a faculty member.

For MDs with little research exposure who may require a longer interval of mentored scientific training, the established $\mathrm{K}$ awards may be appropriate. For MDs with some research experience, a new award mechanism that we call K/Q/R should be considered. The initial $\mathrm{K}$ phase would provide support for 2 years of mentored research training after completion of clinical training, and the Q phase would provide an additional 2 years of mentored research training with an increased budget. If further training milestones are achieved, including appointment to an independent position, the $\mathrm{R}$ phase would provide 3 years of support. Thus, this award mechanism emphasizes uninterrupted career advancement of promising young investigators, rather than requiring them to apply for different grants, which may delay the launch of their career due to the often arduous review process.

In partnership with academic institutions, K99/R00 and $\mathrm{K} / \mathrm{Q} / \mathrm{R}$ programs should be crafted to address the unique challenges faced by physician-scientists as they progress toward research independence. These include (i) providing appropriate titles, salaries, and most importantly, protected time in lieu of increased emphasis by clinical departments on salary support based on RVUs; (ii) establishing career-development programs to enable trainees to achieve career goals; and (iii) evaluating the effect of maintenance of clinical skills during this period of intense research training. Review of applications for this program should place less emphasis on extensive preliminary data and more emphasis on the potential of the applicant and quality of the mentors and structured training experience. We note with approval the recently announced award program from the Doris Duke Research Foundation, which provides institutional funds to support physician-scientists during the push for independence $(19,20)$.
Finally, all K awards should be granted earlier, based on the candidate's potential and the proposed mentoring relationship rather than substantial research productivity. K programs, including the proposed K99/R00 and K/Q/R awards, should be viewed as partnerships between the NIH and the candidate's institution. Together, they should provide the investigator with sufficient funds to begin independent research and sufficient protected time to carry it out in a thoughtful manner.

\section{Action item \#3: Achieve greater diversity and numbers in physician-scientist training programs}

The PSW report shows that the physician scientist workforce is neither large nor diverse. Explanations for this are numerous and include limited advising about the career path, limited numbers of role models, readily apparent attitudes in academia about women and minorities, and unconscious biases. The NIH continues to play an active role in encouraging workforce diversity, using the carrot of institutional training awards to encourage recruitment. As our third action item, we propose new practices to achieve greater numbers and diversity in the physician-scientist pipeline.

Achieve greater numbers. Of the 8,200 physicians who are principal investigators on NIH research awards, half are $\mathrm{MD}-\mathrm{PhDs}$ and half are MDs without a PhD. The PSW advisory committee estimated that approximately 1,000 new physician-scientists need to enter the workforce each year to maintain steady-state. Currently, only half that number is graduating each year from $\mathrm{MD}-\mathrm{PhD}$ programs (20). Although many funded programs exist to encourage medical students to pursue research, only limited data are available about the outcomes of these programs. There also is a paucity of data available on graduates from medical school who become $\mathrm{NIH}$-funded investigators after an extended period of postdoctoral training, a pathway that used to be the most common route to a research career for physicians. Beyond the AAMC graduation questionnaire, there has been little organized effort to study the career paths of physician-scientists who were not enrolled in MDPhD programs. The absence of these data makes it hard to know what influences individuals to pursue careers as physician-scientists and what sustains them going forward.

Although we endorse the PSW report's recommendation to sustain $\mathrm{MD}-\mathrm{PhD}$ training support, we note that the applicant pool for $\mathrm{MD}-\mathrm{PhD}$ programs has barely increased in the past 5 years and currently stands at only 1,800/year, one-third of whom enter a program (Figure 2A). What happens to applicants who are not admitted is not known - nor is it known how many were denied admission because of less than spectacular MCAT scores, a metric that bears little relationship to success in research (21). We strongly support efforts to expand the pool of potential physician-scientist trainees through outreach efforts at all levels, greater engagement with undergraduate prehealth advisors, and an enhanced emphasis on characteristics that count. Additionally, new strategies to reach students prior to entering college should be developed to increase awareness of physician-scientist careers before career goals are firmly established.

Achieve greater diversity. The PSW report noted that, among physician-scientists applying for NIH grants, men outnumber women 3:1. Despite the current gender parity for both medical school and graduate school applicants, only $37 \%$ of MD-PhD program applicants are women, and that proportion is not increasing 
(Figure 2A). Therefore, the gender bias in NIH-funded physicianscientists will continue if gender inequality in the MD-PhD training pipeline is not addressed. Why fewer women than men apply to $\mathrm{MD}-\mathrm{PhD}$ training programs is not known, but this discrepancy should be explored and corrected.

The PSW Working Group also found that three-quarters of the NIH-funded physician-scientists were white, and one-fifth were of Asian descent, but other ethnic and racial groups were underrepresented. Data about the racial and ethnic backgrounds of applicants for $\mathrm{MD}-\mathrm{PhD}$ programs indicate that the pipeline for these underrepresented groups is small and not improving (Figure 2B). Increasing the number of students from diverse backgrounds in $\mathrm{MD}$-PhD programs, and biomedical science in general, should be a top priority.

A number of undergraduate programs have been successful in recruiting increased numbers of underrepresented students into research, including the Meyerhoff Scholars Program at the University of Maryland-Baltimore County (22) and the Freshman Research Initiative, initiated at the University of Texas at Austin and now implemented at additional schools through Howard Hughes Medical Institute funding (23). These and other successful programs should be implemented nationwide to improve and diversify the pipeline for the PSW. At the same time, factors that decrease the success of underrepresented minorities must be addressed, such as the recent report that African-American applicants are 10 percent less likely than whites to be awarded NIH research funding (24).

\section{Action item \#4: Mentoring and oversight of physician-scientist trainees at all levels should be centralized to reduce attrition}

Harmonize physician-scientist training institutionally. As our final action item, we urge the establishment of institutional physicianscientist career development offices specifically tasked to oversee career development programs for physician-scientists to help overcome their major barriers at various stages of training - barriers that include funding, uneven departmental or divisional support, and insufficient mentorship $(25,26)$. Leaders of such offices should have sufficient executive authority to coordinate the breadth of physician-scientist training activities within the institution. These offices should synergize with MD-PhD programs and NIH-funded CTSA centers. This type of centralized oversight has demonstrated excellent early outcomes at Vanderbilt University School of Medicine (27).

A critical component of this office would be to help establish mentorship teams for trainees that would include research, career, and peer mentors who would meet regularly with the physicianscientist to oversee his/her progression from graduation to independence. Since some institutions may not have appropriate NIHfunded investigators capable of serving as role models or mentors, we propose that a national physician-scientist mentoring network be established. This network would include a structured cross-institutional mentoring program and could be established with the support of multiple national specialty clinical societies. This network also could be supported by the NIH (similar to the new National Research Mentoring Network). We note that this type of mentor matching has promoted the transition to independence for Geriatric Mental Health physician-scientists $(28,29)$. With the advent of Web-based conferencing, the optimal mentors for a physicianscientist could be recruited, regardless of institutional affiliation.
Physician-scientist career development offices would be tasked with many aspects of career development training, including training in quantitative sciences, clinical trials, medical bioethics, collaboration and research team participation, grant proposal preparation, oral and written presentations, finances, leadership, negotiation, conflict resolution, and many other topics. Trainees would be able to choose from these topics to develop highly individualized training and career development plans. This office would be responsible for collecting institutional data to track career outcomes, reasons for attrition, and institutional efforts to shorten the holding zone. Finally, the office would help create a welcoming and supportive environment for physician-scientists and facilitate a community for these individuals at each institution.

Pursue a national emphasis on postgraduate physician-scientist training. Bringing together program leaders from across the nation to share ideas and best practices benefits everyone, and similar efforts should be developed for postgraduate physician-scientist training. It is likely that the establishment of a similar group for research residency and fellowship directors would immediately improve the quality of postgraduate physician-scientist training. Currently, oversight of physician-scientists in training is often the responsibility of residency program directors who, by necessity, tend to focus on clinical training requirements and the majority of residents who seek full-time clinical careers. Thus, this oversight is often insufficient and not appropriate for the mentoring needs of a developing physician-scientist. Additionally, many of these research residency and fellowship programs have only one or two trainees. Sharing effective training strategies across programs and providing opportunities for trainees to interact will likely enhance a sense of community for these future physician-scientists.

\section{Conclusion}

We propose four actions that can be taken now to sustain the PSW by attracting new members, reducing attrition, shortening the pipeline, and providing proper training and oversight. Since it is not always in the best interest of an institution or a department chair to promote research over clinical care for physicianscientist trainees and faculty members, national organizations such as the Academy of Medicine, the American Society for Clinical Investigation, AAMC, and the Association of American Physicians should be involved to proactively address how most effectively to support physician-scientist training and careers. Absent such efforts, we foresee a steady decline in workforce numbers and biomedical research success as the remaining physicianscientists turn off the office lights for the last time.

\section{Acknowledgments}

We thank the many members of the MD-PhD training community for contributing to discussions about the PSW. See Supplemental Acknowledgments for the National Association of MD-PhD Programs Executive Committee details.

\section{About the authors}

Dianna M. Milewicz, MD, PhD, is the President George H.W. Bush Chair of Cardiovascular Medicine and Director of the Division of Medical Genetics at University of Texas Health Science Center at Houston (UT Health). She directs the joint MD-PhD 
Program between UT Health and MD Anderson Cancer Center. Her research is directed toward understanding the genetic basis of vascular diseases, including thoracic aortic aneurysms, aortic dissections, and early-onset strokes.

Robin G. Lorenz, MD, PhD, is a professor of pathology who specializes in clinical pathology with a focus on clinical immunology and laboratory utilization. She is also the associate dean for physician-scientist development and oversees the UAB MSTP, the UAB Summer Medical Student Research Program (MSSRP), the Preparation for Graduate and Medical Education (PARAdiGM) Program, and the UAB Summer in Biomedical Sciences (SIBS) Undergraduate Research Program. Her research focuses on mucosal immunology and autoimmune diseases.

Terence S. Dermody, MD, is the Dorothy Overall Wells Professor of Pediatrics and director of the MSTP and Division of Pediatric Infectious Diseases at Vanderbilt University School of Medicine.
He also is a professor of pathology, microbiology, and immunology at Vanderbilt and adjunct professor of biomedical sciences at Meharry Medical College. Dermody's research focuses on viral pathogenesis, vaccine development, and medical education.

Lawrence Brass, MD, $\mathrm{PhD}$, is a professor of medicine and professor of systems pharmacology and translational therapeutics at the University of Pennsylvania Perelman School of Medicine, where he studies mechanisms of thrombosis and hemostasis, and serves as associate dean for Combined Degree and Physician Scholars Programs, director of Penn's MSTP, and director of the Hematology Research Training Program.

Address correspondence to: Dianna M. Milewicz, Department of Internal Medicine, University of Texas Health Science Center at Houston, 6431 Fannin, MSB 6.100, Houston, Texas 77005, USA. Phone: 713.500.6715; E-mail: dianna.m.milewicz@uth.tmc.edu.
1. NIH. Physician-scientist Workforce (PSW) Working Group Report. NIH Web site. http://acd.od.nih.gov/reports/PSW_Report ACD_06042014.pdf. Updated June 1, 2014. Accessed August 13, 2015.

2. NIH. Biomedical Research Workforce Working Group Report. NIH Web site. http://acd.od.nih. gov/biomedical_research_wgreport.pdf. Updated June 14, 2012. Accessed August 13, 2015.

3. Brass LF, Akabas MH, Burnley LD, Engman DM, Wiley CA, Andersen OS. Are MD-PhD programs meeting their goals? An analysis of career choices made by graduates of $24 \mathrm{MD}-\mathrm{PhD}$ programs. Acad Med. 2010;85(4):692-701.

4. American Board of Internal Medicine. Research Pathway Policies \& Requirements. ABIM Web site. http://www.abim.org/certification/policies/ research-pathway-policies-requirements.aspx. Accessed August 13, 2015.

5. The American Board of Pediatrics. Integrated Research Pathway in Pediatrics. ABP Web site. https://www.abp.org/content/integratedresearch-pathway-irp. Updated February 16, 2013. Accessed August 13, 2015.

6. The American Board of Pediatrics. Accelerated Research Pathway in Pediatrics. ABP Web site. https://www.abp.org/content/acceleratedresearch-pathway-arp. Updated January 14, 2015. Accessed August 13, 2015.

7. American Board of Pathology. The American Board Of Pathology Physician-Scientist Research Pathway. ABP Web site. http://www.abpath.org/ PHYSICIAN-SCIENTIST_RESEARCH_PATHWAY1.pdf. Updated September 5, 2014. Accessed August 13, 2015.

8. The American Board of Radiology. Holman Research Pathway in Radiology. ABR Web site. http://www.theabr.org/ic-dr-holman-pathway. Accessed August 13, 2015.

9. The American Board of Radiology. Holman Research Pathway in Radiation Oncology. ABR Web site. http://www.theabr.org/ic-ro-holmanpathway. Accessed August 13, 2015.

10. The American Board of Dermatology. Requirements For Eligibility To Take The Examination. ABD Web site. http://www.abderm.org/resi- dency/residency.html. Accessed August 13, 2015.

11. Lipner RS, Lelieveld C, Holmboe ES. Performance of physicians trained through the research pathway in internal medicine. Acad Med. 2012;87(11):1594-1599.

12. Todd RF 3rd, et al. Career outcomes of the graduates of the American Board of Internal Medicine Research Pathway, 1995-2007. Acad Med. 2013;88(11):1747-1753.

13. UCLA STAR Program. UCLA Web site. http:// star.med.ucla.edu/. Accessed August 13, 2015.

14. Muslin AJ, Kornfeld S, Polonsky KS. The physician scientist training program in internal medicine at Washington University School of Medicine. Acad Med. 2009;84(4):468-471.

15. Paik JC, Howard G, Lorenz RG. Postgraduate choices of graduates from medical scientist training programs, 2004-2008. JAMA. 2009;302(12):1271-1273.

16. Arbuckle MR, Gordon JA, Pincus HA, Oquendo MA. Bridging the gap: supporting translational research careers through an integrated research track within residency training. Acad Med. 2013;88(6):759-765.

17. Dzirasa K, Krishnan RR, Williams RS. Incubating the research independence of a medical scientist training program graduate: a case study. Acad Med. 2015;90(2):176-179.

18. Tsai AC, Ordonez AE, Reus VI, Mathews CA. Eleven-year outcomes from an integrated residency program to train research psychiatrists. Acad Med. 2013;88(7):983-988.

19. Doris Duke Charitable Foundation. Fund to Retain Clinical Scientists. http://www.ddcf. org/Programs/Medical-Research/Goals-andStrategies/Build-the-Clinical-Research-CareerLadder/Fund-to-Retain-Clinical-Scientists/. Accessed August 13, 2015.

20. Association of American Medical Colleges. Enrollment, graduates, and MD-PhD Data. AAMC Web site. https://www.aamc.org/data/facts/enrollmentgraduate/. Accessed August 13, 2015.

21. Bills JL, VanHouten J, Grundy MM, Chalkley R, Dermody TS. Validity of the Medical College Admission Test for predicting MD-PhD student outcomes [published online ahead of print
May 8, 2015]. Adv Health Sci Educ Theory Pract. doi:10.1007/s10459-015-9609-x.

22. Maton KI, Pollard SA, McDougall Weise TV, Hrabowski FA. Meyerhoff Scholars Program: a strengths-based, institution-wide approach to increasing diversity in science, technology, engineering, and mathematics. Mt Sinai JMed. 2012;79(5):610-623.

23. The University of Texas at Austin. Freshman Research Initiative. UT Web site. https://cns. utexas.edu/fri. Accessed August 13, 2015.

24. Ginther DK, et al. Race, ethnicity, and NIH research awards. Science. 2011;333(6045):1015-1019.

25. Ogdie A, et al. Barriers and facilitators of a career as a physician scientist among rheumatologists in the United States [published online ahead of print February 23, 2015]. Arthritis Care Res (Hoboken). doi:10.1002/acr.22569.

26. Tong CW, et al. Challenges facing early career academic cardiologists. J Am Coll Cardiol. 2014;63(21):2199-2208.

27. Brown AM, et al. Centralized oversight of physician-scientist faculty development at Vanderbilt: early outcomes. Acad Med. 2008;83(10):969-975.

28. Bruce ML, Bartels SJ, Lyness JM, Sirey JA, Sheline YI, Smith G. Promoting the transition to independent scientist: a national career development program. Acad Med. 2011;86(9):1179-1184.

29. Daye D, Patel CB, Ahn J, Nguyen FT. Challenges and opportunities for reinvigorating the physician-scientist pipeline. JClin Invest. 2015;125(3):883-887.

30. Association of American Medical Colleges. FACTS: Applicants, Matriculants, Enrollment, Graduates, $\mathrm{MD} / \mathrm{PhD}$, and Residency Applicants Data. Table 32: MD-PhD Applicants, Acceptees, Matriculants, and Graduates of U.S. Medical Schools by Sex, 2001-2012. AAMC Web site. https://www.aamc. org/data/facts/. Accessed May 15, 2015.

31. Association of American Medical Colleges. Table 32 M.D.-Ph.D. Applicants to U.S. Medical Schools by Race/Ethnicity and State of Legal Residence, 2014. AAMC Web site. https://www.aamc.org/ download/321542/data/factstable32.pdf. Accessed May 15, 2015. 